\title{
Nos territórios do corpo: práticas e deslocamentos audiovisuais ${ }^{*}$
}

\author{
Monica Toledo Silva \\ Universidade Paulista / Universidad Estatal de Campinas / \\ Universidad Federal de Minas Gerais \\ monica1605@gmail.com
}

\begin{abstract}
Resumo
O artigo aborda a transitoriedade de conceitos científicos e propõe outros entendimentos para práticas do corpo nos contextos do nomadismo de linguagens estéticas, aderentes ao trânsito de indivíduos migrantes, em estados que são atualizados a cada tempo e lugar em vivências nas quais convergem futuros e passados. Estas vivências ganham sonoridades e visibilidades singulares coerentes com suas realidades sobrepostas, e viabilizam uma prática audiovisual de forma e sentido também fluidos para os deslocamentos contemporâneos. O texto busca formas para conteúdos do corpo, estéticas para discursos possíveis, mapeamentos provisórios de deslocamentos individuais em territórios configurados dinamicamente por estados de presença.
\end{abstract}

Palavras-chave

Deslocamento, audiovisual, corpo, refúgio, narrativa.

\section{En los territorios del cuerpo: prácticas y dislocaciones audiovisuales}

Resumen

El artículo trata de la transitoriedad de los conceptos científicos y propone comprensiones diversas para las prácticas del cuerpo en los contextos del nomadismo de lenguajes estéticos; adherentes al tránsito de individuos migrantes, en estados de actualización a cada tiempo y lugar en vivencias en las cuales confluyen futuros y pasados. Estas vivencias ganan sonoridades y visibilidades singulares y coherentes con las realidades sobrepuestas, vizibilizando una práctica audiovisual de forma y sentido también fluidos para las dislocaciones contemporáneas. Em el texto se buscan formas para los contenidos del cuerpo, estéticas para discursos posibles, mapeos provisorios de dislocaciones individuales en territorios configurados dinámicamente por estados de presencia.

Palabras clave

Dislocación, audiovisual, cuerpo, refugio, narrativa.

* Recibido: 27 de julio de 2017/ Aceptado: 29 de noviembre. 


\title{
Embodied territories: audiovisual practices and dislocations
}

\begin{abstract}
This article discusses the transitoriness of scientific concepts and proposes other understandings for body practices in the context of nomadic aesthetic languages, adherent to migrant individuals who constantly change their state of mind and place, and whose experiences converge the future with the past. These experiences obtain singular sounds and visibilities that are coherent with their overlapping realities, and enable audiovisual practices of form and meaning, which are also fluid for contemporary movements. This article seeks to reveal forms for body contents, aesthetics for possible discourses, and provisional mappings of individual displacements in territories dynamically configured by states of presence.
\end{abstract}

Keywords

Dislocation, audiovisual, body, refuge, narrative. 
A realidade dada através do corpo rompe com a significação (...). O que conta é o que se passa nas imagens, e o próprio tempo que passa entre os movimentos, com seus aspectos de petrificação, cristalização, decomposição. O corpo pode estar presente e ausente, e quando está presente ele sai da linha contínua do tempo que corre determinado pela ação, a significação, a economia, a representação do mundo. É um outro tempo que surge na ferida dessa linha rompida (Kuniichi Uno, 2012).

As narrativas do corpo, como criadoras de nossa própria história, demandam uma busca epistemológica híbrida. Performances contemporâneas se apropriam de enunciados diversos para melhor representar uma realidade, os limites da ficção, o mundo do outro, a fantasia, o cotidiano, a criação de visibilidades para acontecimentos e a produção artística e política. A proximidade destas performances do corpo (como cada indivíduo age desde suas realidades e repertórios) e suas imagens (o que produzem em seus contextos pessoais e sociais) formula aqui uma tessitura como possibilidade de percepção, troca e ação com o outro.

A porosidade como estratégia de sobrevivência (as trocas comunicacionais e atualizações de um discurso que geram novas possibilidades de coexistência, a partir da superfície da pele como metáfora desse lugar da troca no corpo), os experimentos de pertencimento e do tempo como intensidade, vêm inspirar práticas audiovisuais em suas vertentes da performance e instalação -mídias que melhor contextualizam esta realidade de aderência ao lugar transitório, com imagens que cartografam singularidades em estados de suspensão e de reorganização do corpo enquanto lugar de refúgio do próprio.

Traçados oficiais de fronteiras entre países submergem em realidades híbridas de trocas culturais, negociações linguísticas e aprendizados de sobrevivência -a exemplo dos extensos campos de refugiados na Jordânia, Líbano e Turquia, para os "sortudos" que chegaram de outros grandes campos (na Líbia e Moçambique por exemplo), em percursos de vários anos que incluem perdas e danos de toda natureza, para assentarem também/ainda/sempre provisoriamente e em chegadas conturbadas e dramáticas nas costas da Itália e Grécia para um novo ainda/ sempre sem destino e já sem desejo.

Compreender o espaço da fronteira como o de coexistência e criação de novos significados é perceber estes lugares de passagem, onde territórios se diluem em novos meios de (re)configuração de nossos mapas e histórias. Nosso destino é o trajeto; o meio torna-se o lugar. Para este corpo em situação proponho uma montagem-pensamento, desde registros performados de estados vivos numa obra que revela sons e imagens como intensidades. A estética do provisório/transitório invade a captação de áudios e dialoga com ficções, memórias, cantos e contos. 0 
que seria real em um conjunto de veracidades simultâneas e heterogêneas, de sensações genuínas, descontínuas e simultâneas de estados de presença que alternam ausências e estados de presença?

Pensar hoje nas imbricações semióticas e nos alcances dos pensamentos de Lotman, Jakobson, e mais tarde Saussure e escolas derivadas da semiótica da cultura desde sua origem russa na linguística sempre contaminada pelas artes, é ao mesmo tempo estar no mundo, sensível a ele, atento aos desdobramentos e convergências das linguagens da arte que sistematicamente criam representações (apresentações) do corpo móvel e afetado por seu entorno -que também é feito por ele. Assim, entre partidas e chegadas, desvios de sentido e potências significantes, (re)encontramos essa semiótica desde sempre híbrida e propomo-nos a investigá-la desde nossos afetos e subjetividades.

Num contexto paralelo de evoluções epistemológicas, mas neste caso de efeito inverso, ou seja, não de elucidação ou inspiração, mas sim de desorientação, estão as categorizações tradicionais dos gêneros audiovisuais -originalmente cinematográficos- como documentário, experimental, cinema verdade, mídias móveis (não seriam todas?), drama, clássico, etc. Catalogar acontecimentos históricos, complexos por excelência, em critérios rígidos ao invés de tratá-los como conteúdos enredados, híbridos e transdisciplinares é um desserviço aos estudos de linguagem das mídias e do corpo, logo, dos fenômenos multifacetados que compartilhamos e vivenciamos.

As realidades múltiplas e particulares quando apartadas do recurso da fala resinificam o papel do corpo na imagem desde contextos especificamente visuais. Tratar realidades tantas vezes dramáticas como meios onde os sentidos deslizam em formas diversificadas de contato, captação e exibição, promove vivências particulares em obras que podem ser atualizadas ou adaptadas às condições de cada novo espaço de exibição -que, por sua vez, agrega qualidades próprias de visualidade tanto quanto de sonoridade, ao lembrarmo-nos que o áudio é sempre autônomo na criação de formas narrativas, estéticas e expressivas, sem nunca precisar subjugar-se à imagem e sempre em diálogo com o tempo e lugar.

O corpo é, no fazer artístico, resultado momentâneo de várias interferências espaço temporais, antropófago de imagens sem origem. Uma narrativa do corpo é performance em qualquer mídia: é circunstancial e contextualizada. Imagem são ações que se atualizam no fazer a obra, compondo nela ruídos, afetos, durações e intensidades e assim novas imagens, móveis, logo nômades, e dialógicas com o espaço que também as determina. Pensar em imagens a situação de um corpo: incompleta, atualizada, informe, em estado de troca com o entorno.

Os conteúdos de um corpo que cria são imaginações, desejos, emoções em processo e no fluxo do mundo; conteúdos instantâneos que agregam às memórias e 
paisagens de cada um; conteúdos de invisibilidade. O sentido de tempo vive atrelado ao desejo de mapear vivências. Como vivem estes indivíduos no nomadismo? Como captá-los, que espaços ocupam e que visibilidades criam nas formas cotidianas reinventadas?

\section{O audiovisual como forma}

$\mathrm{O}$ ato de registrar este movimento nômade leva à qualidade da mobilidade, da percepção afetada, das intensidades experienciadas em trocas e apresentações de si. A forma e conteúdo de uma obra (escrita, encenada, declamada, tocada, dançada, filmada) varia com cada exercício de perceber o outro e, assim, sua duração e apropriação do tempo e do espaço em forma estética singular. O impasse da representação formal única e orientadora resgata a realidade "real", plural e potente alude à noção de sintaxe, como num sistema que articula partes, do corpo em imagens sensórias, como agente e meio de subjetividades.

Na linguagem da instalação e da performance audiovisuais o corpo é estético, semiótico, objeto, sujeito, agente, acenando para possíveis narrativas migrantes, experimentos audiovisuais. Videoperformance e videoinstalação são territórios particulares e deslocados; linguagens audiovisuais são coerentes com a prática também nômade. Em função da não linearidade destes suportes midiáticos -a exemplo das projeções simultâneas, audios sobrepostos e objetos cênicos agregáveis- remetendo à linguagem das videoarte e desta para canais múltiplos de representação, apresentação, comunicação, produções de sentido. Como se politiza a arte nas expressões de um corpo que atravessa espaços agregando discursos singulares, manifestos em obras e presentificadas de estados de si?

O filósofo Georges Didi-Huberman lembra Benjamin -pra quem "a dialética faz proceder dos extremos afastados, onde oposições podem coexistir de uma maneira que faça sentido" (2011: 110, 112)- e pondera que não se pode ignorar a "capacidade de suspensão, de transformação, de bifurcação. O paradigma perdeu sua própria potência: sua potência de sintoma, de exceção, de protesto em ato" (2011: 110, 112).

A linguagem da performance audiovisual passa pelo texto e produção de imagens em técnicas e registros diversos, da voz ao desenho, do super8 à dança, do poema ao palco. A videoinstalação é lugar de excelência de sequências não lineares, como um olhar múltiplo. O público, entre visitantes e participantes, é também personagem: são todos "uns", com suas próprias histórias. Como elaborar narrativas neste espaço híbrido e latente? Como gerar um ambiente de troca com estas artistas-personagens para a realização das obras? E, antes, como criar no estado de aporia? 
Os recursos da estética do provisório ou transitório incluem a captação de áudios em suportes e técnicas variadas, cada um contemplado à sua forma a ficção, em histórias, cantos e contos, silêncios. O que seria real em um conjunto de veracidades simultâneas e heterogêneas, de sensações genuínas e estados de presença que alternam presentes e intensidades? A montagem sonora pode privilegiar um estado de suspensão, de sonoridades difundidas em ruídos de falas, de línguas variadas, sem que a palavra carregue um sentido próprio, em paisagens sincronizadas mais com memórias e estados de atenção que nas imagens produzidas, veículos de outros lugares e afetos.

O conteúdo subjetivo é por natureza imapeável e oxigena um conhecimento ainda indefinível (como comunicação, psicologia, antropologia, história e ciências políticas). As narrativas do corpo como imagens móveis, num contexto de exposição ou de apresentação num ambiente instalativo, apresentam-se como um pensamento-performance, que (inter)age com minhas percepções, também contaminatórias, e que implodem fronteiras prévias entre arte e ciência, ciência e filosofia, arte e natureza etc. Uma tecitura de anônimos de um estado de deriva que precede um estado de presença e convive com ele em trajetos de (in)visibilidade, numa simultaneidade acrônica e singular, reavivando as fronteiras de outros espaços em expansão.

Imagens são ações que se atualizam no fazer da obra, compondo nela temporalidades, espacialidades, especificidades, ruídos de linguagem, no contexto onde se configuram. Esta compreensão do fazer diz respeito a composições narrativas tal qual o próprio discurso se apresenta ao mundo: estímulos simultâneos, exercícios estéticos, falas interruptas, esquecimentos, distrações, abandonos (a esse estado híbrido eu chamo performativo e aberto, atento e disperso). Como esta qualidade visual é presente hoje nas mídias digitais e nas linguagens cênicas, na tela ou no museu? As visualidades e sonoridades fragmentadas instigam nomenclaturas delimitadoras -performance, vídeo, live cinema, instalação, e formas orais e de registro, montagem e representação. Formas correntes de apresentação de si visitam categorias midiáticas e se reconfiguram num corpo audiovisual hibridizado e congruente artístico e científico, que renova constantemente formas de apresentação do sujeito em suas subjetividades.

As formas de mapeamentos pessoais aludem a paisagens visitadas, inventadas, rememoradas, resinificadas. A intensidade e a duração de cada lugar, pessoa e objeto atestam presenças possíveis e acenam para formas narrativas curtas, longas, claras, escuras, desfocadas, estouradas. As paisagens arruinadas, que apresentam cenários de acontecimentos passados num aparente abandono -lugares onde o mato cresce livremente, as paredes mudam de cor, ganham umidade e buracos, deterioram-se para revelar outras formas de vida- são um dos mais fortes sinais de como o corpo ocupa lugares mesmo quando deixa de estar 
fisicamente presente: as ruínas são também narrativas dos corpos que ali agiram e criaram o lugar, junto com a natureza, seus bichos, plantas e tempos.

Assim, mapear paisagens passa a ser exercício também do corpo, que se desloca com seus impulsos e ruínas próprias, reconfigurando-se, assim como os lugares vazios que contam histórias dos outros, em tempos e espaços múltiplos e simultâneos: o tempo de cada um no andar, no ver, que leva passados e futuros e que se estende no espaço oferecendo-se em formas materializadas em gestos, traçados móveis, como um bordado na parede e uma cicatriz na pele -mapas de percursos aleatórios que não precisam de significados e que agem como potência e estado do aberto.

As experiências de registros em conjunto com a pesquisa formal têm a oralidade suprimida de seus termos orientadores, sem favorecer conteúdos explicativos, e lembram um cinema moderno dos anos 1920, em relação às ausências narrativa e de linearidade, e 1960, como em Alain Resnais, Krzysztof Kieslówski e Michelangelo Antonioni, nas suas práticas de captura, montagem e conjugação de um espaço-tempo particular de narrativa menos evidente.

Realidades distintas requerem uma percepção ativa e uma ação conjugada com o tempo e o espaço do lugar, enquanto ignição para criação autoral, assim como de ação a cada tempo afetada e atualizada. A noção de performatividade ${ }^{1}$ dialoga com a fenomenologia ${ }^{2}$, especialmente exposta por Maurice Merleau-Ponty e é experimentada no corpo sujeito-objeto-agente visíveis e visuais. O exercício da pesquisa e criação de pontes epistemológicas entre mundo e corpo gerado nos experimentos nos lembra que a produção de conhecimento se dá no corpo do artista e sua paisagem (num estado provisório e subjetivo de soluções -gestos, procedimentos, visualidades, em solução circunstanciada de seus rastros, ruídos e afetos). A presença no que permanece objeto, afeto, território e lugar A presença no que permanece objeto, afeto, território e lugar.

Este exercício performático é também um encontro da disponibilidade, desde um estado de presença do realizador (muitas vezes performer) que compõe formatos e estéticas variadas, no momento da captura de imagens, de sons, na ação

\footnotetext{
${ }^{1} \mathrm{O}$ conceito de performatividade refere-se a um modo de estar no mundo e pode ser aplicado às relações pessoais, sociais, políticas, culturais, artísticas. A noção subverte procedimentos que fixem ideias, pensamentos e produções a favor de um "como" que precisa sempre ser construído em fazeres que levam a dizeres específicos; a performatividade substitui unidade por singularidade (Sobreira, 2008).

${ }^{2}$ Fenomenologia: o "como" do fenômeno, percepção da experiência vivida, sem limitar-se a uma gênese ou dinâmica. Ajusta-se a toda emergência, assumindo-a até o fim; faz uso de uma linguagem do mundo em que estamos imersos; é comunicável e adiagnóstica. Referências psicológicas, biológicas e sociológicas são apreendidas pelo fenômeno da experiência direta das coisas, acontecimentos, emoções, vivências (Maldonato, 2014).
} 
de dirigir e de editar. Assim como o ambiente, o corpo cria uma comunicabilidade inspirada por suas próprias ações, por sua vez movidas por intenções e afetos, e que também se configuram no contexto, sendo assim coadjuvantes dos resultados.

Estes estados de presença, de atenção e desvio, inspiram ou provocam uma determinada linguagem estética, provocada por um corpo visível tanto na câmera (quando filma) quanto na imagem (quando atua). Esta qualidade de dirigir e atuar acaba por fundir-se numa só: o mesmo artista-realizador-performer é o diretor (determina durações, cortes, planos, focos, posições de equipamentos e posicionamentos de intérpretes) e o ator (determinando por outras vias também durações -quanto irá durar seu olhar ou a velocidade de um movimento de perna; focos- se ele se aproxima demais da lente num gesto brusco o equipamento o captará como um rastro; etc., num jogo infinito de mapeamentos provisórios, seja num espaço cênico controlado, seja numa locação aberta e sujeita a muitas outras variações de plano, cortes, luz e som, etc. A paisagem criada no estúdio, a paisagem criada no corpo, a paisagem criada pelo lugar, todas dialogam com o ato do artista realizador-performer de estabelecer em seu conteúdo próprio seus próprios mapeamentos -registros (para a câmera), pontos (para a edição), fraturas (para as ruínas).

A imagem presentifica-se como a estratégia do gesto como um novo exercício de mapear, e agrega toda forma de ruídos e outras sonoridades que habitam o ambiente cênico expandido com toda sua variedade de estímulos sensórios. Artistas encontram em suas próprias linguagens suas maneiras de ver e serem afetadas, e de abrigar-se num território físico (lugar) ou mental (corpo). O que abriga? O que se preserva entre lapsos e presenças ausentes? A paisagem se mostra sempre como um estado-forma, solução afetada.

\section{O corpo como território}

A Grécia é hoje um dos principais países de chegada e fluxo de centenas de milhares de refugiados rumo a outros países europeus; uma de suas ilhas que mais tem provisoriamente abrigado estes migrantes é Kos, localizada no mar Egeu, cujo significado em catalão é corpo -cos, por sua vez originado de cosmos, do grego kosmos: o mundo.

A condição contemporânea de uma cartografia móvel no deslocamento geográfico oferta à linguagem estética das imagens novas propriedades móveis, assim como sonoridades, nesta potência evolutiva de um estado de deriva para um estado de presença. Como criar na imagem (também movente) a experiência do deslocamento em seu momentâneo pertencimento? Conceber imagens para cartografias irregulares, assim como para espaços criados no corpo, resulta numa 
obra nômade, flutuante, que materializa possibilidades em obras não narrativas e mapas pessoais, onde as técnicas de captura e exibição agem como coadjuvantes na criação de sentido.

Uma informação tem um sentido em determinado contexto espaço-temporal e quando transportada carrega consigo variações para um novo entendimento, em novo lugar. Por isso o peso (histórico, afetivo, imaginativo) que damos aos fatos muda ao longo do tempo, o que nos permite agregar, abandonar, transformar significados no corpo naquele instante e lugar. A forma e conteúdo de cada captura também varia com o estado de presença do corpo e suas próprias vivências e subjetividades. Estes gestos de mobilidade audiovisual exibirão formas estéticas para as perdas, descobertas, desejos, segredos de indivíduos protagonistas de histórias até então invisíveis, nesse conjunto proposto de obras videográficas e sonoras que formaliza uma obra instalativa que comunica estados corpóreos em trânsito, processos nômades do corpo fenomênico.

O entendimento do corpo como (re)percussor de intensidades e afetos conduz esta proposta criativa a situações atópicas. Conceber paisagens para artistas migrantes, a partir de minha percepção e porosidade, expõe a vulnerabilidade e evolução de conteúdos pessoais para novas formas de visibilidade: como traduzir e apresentar um passado distante geograficamente num presente plural de afetos que ficam e que buscam nova forma de apresentação?

A criação de imagens é uma performance do corpo a partir do entendimento híbrido de corpo e cinema -ambos feitos de tempo, espaço, movimento e imagem- em conjunção com os signos visuais e sonoros emergentes. Um cinema do corpo problematiza seus meios de exibição e suportes de realização, com ruídos, espaços cheios e vazios, lugares estrangeiros, paisagens abertas, cenas inacabadas -estados entrópicos. Além de apontar linguagens do corpo (sua dramaticidade, expressividade, carga emotiva, surpresas, sustos) há estéticas sempre inéditas para estas narrativas corpóreas. Cinema como performance do corpo: lugar de reinvenção de tempos e espaços, deslocamento e paisagem.

A pesquisadora brasileira Christine Greiner sugere que o entendimento do corpo como processo (acontecimentos unidos por redes de relações) traça visibilidades de processos criativos das personagens em seus sentidos e linguagens narrativas próprias. Percebendo hipóteses como inquietações -que se tornam também políticas quando organizadas como ação-, podemos compreender estes gestos estrangeiros como ações abertas à troca e à formulação de novas paisagens, assim como a transição de saberes e práticas que no novo lugar agirão compondo conteúdos inéditos. O corpo passa a ser o lugar do próprio, à parte de sua localização espacial. 
Para o italiano Giorgio Agamben (2012) o corpo seria um "laboratório do devir", dando abertura a teorias que transmutam em existências corpóreas, jogos de forças de valoração de sentidos. Apreender o conceito de imagem também como um jogo de intensidades, como proponho aqui, potencializa as representações formais dos conceitos de territorialidade, presença, porosidade, nomadismo, para novas possibilidades de apresentação do próprio corpo em suas realidades aderentes e diluídas em vivências fragmentadas.

O filósofo sugere que o silêncio "não é uma simples suspensão do discurso, mas silêncio da própria palavra, a palavra tornar-se visível: a ideia da linguagem. (...) $E$ não nos foi dada a linguagem para libertarmos as coisas das suas imagens, para conduzi-la à glória?" (Agamben, 2012: 112;125).

O não-lugar exposto na morada provisória, na suspensão das estabilidades culturais, o estado de latência do aberto, faz lembrar que quem cria o lugar é o corpo e esta noção não é geográfica nem histórica, mas pessoal; deslocar para preservar, em processos ativos e traçados provisórios, afetos que se atualizam no deslocamento. Compreender o espaço da fronteira como de coexistência e criação de novos significados é perceber estes lugares de passagem, onde identidade e território se diluem em novos meios de (re)configurarmos nossos mapas e nossas próprias histórias. Nosso percurso é o trajeto, o meio que torna-se o lugar. Para este corpo em situação, proponho uma montagem-pensamento, que revele estados vivos numa obra do corpo em crise, de imagens como intensidades em atos performativos. A narrativa do corpo é performance em qualquer mídia: é sempre circunstancial e contextualizada.

Estes gestos de mobilidade dão vida a novas performances narrativas, agindo como visibilidades e sonoridades para estados provisórios de expressão. Tais práticas demandam uma reinvenção de conceitos de imagem e performance para temas vivos e transitórios, coerentes com as vivências contemporâneas de nomadismo e migração, assim como das ações cognitivas que regem novas significações e apontam para a criação de um pensamento mais confluente e poroso, reafirmando o audiovisual como um lugar ímpar de criação de subjetividades tão pessoais quanto políticas.

Assumir por objeto a experiência artística, no território nômade do corpo e do lugar, abre para o universo do outro. Franklin Leopoldo e Silva sugere que articular é "preservar o que faz como que algo seja ele mesmo e encontrar o modo de apreendê-lo como outro ${ }^{3}$, de maneira que o lugar da diferença não faça desaparecer particularidades. (...) A experiência imediata é a do movimento e da mudança, da transitoriedade onde o caráter efêmero das coisas impõe-se". O sujeito,

\footnotetext{
${ }^{3} \mathrm{O}$ autor discorre nesta obra, O outro, sobre o tema da intersubjetividade, inspirado em Emmanuel Lévinas.
} 
"contínua construção que depende de si e dos outros -e por isso é sempre outro, puro processo, e nunca algo consolidado- existiría na multiplicidade, uma forma de busca da unidade do mesmo" (2012: 15).

A linguagem estética da instalação é a que melhor representa a formação de discursos de passagem, sem continuidade nem fim, em acordo com a situação de artistas que experimentam em suas obras processos contínuos de significação, seja no espaço físico (campo de refugiados, casa de parentes, abrigos provisórios) ou seja no próprio corpo, que memoriza e transforma percepções e experiências.

Percebendo a imaginação como parte da realidade, a todo instante atravessado por novas imagens, e o afeto como desestabilizador de certezas, como lidar com a fantasia sem que esta deixe de ser parte do cotidiano? A linguagem da videoinstalação, que permite visualizações simultâneas em função das projeções multiplicadas, reafirma narrativas agregadoras de um conjunto de diferenças, e supre o cruzamento dos estudos de imagens das artistas ao reelaborar suas próprias obras a partir do olhar do outro / da outra.

Mesmo abrigados pelo discurso acadêmico terminamos invariavelmente invadindo o terreno de nós mesmos. Ocupando nossos próprios territórios, reencontramos formas que insistem em virar histórias. Problematizar construções de sentido frente a uma tentativa de ordenação de discursos políticos e autorais é campo de pesquisa de teóricos de áreas distintas, da filosofia aos estudos da imagem e da linguagem (Felix Guattari, Hans Ulrich Gumbrecht, Paul Zumthor, Nicolas Bourriaud, Maurice Blanchot) ${ }^{4}$, assim como abordar a subjetividade de fenômenos que incidem nos modos de vida contemporâneos -como os aqui mencionados Giorgio Agamben e Georges Didi-Huberman, além dos brasileiros.

O discurso fraturado, aparentemente incompleto, parcialmente visível, é o discurso possível de todo corpo e de toda mídia, em seu estado natural (ou virtual, ou eletrônico); como mídia somos sempre parciais; como corpo somos sempre devir. Portanto, qualquer discurso é sempre parte de um todo que não se mostra -seja porque não é a intenção do artista-performer-realizador de revelar um sentido, faceta ou conteúdo visualmente, seja porque seu próprio corpo (devir) não se mostrará pleno, a não ser na imaginação do ato: de quem realiza e de quem vê e é por ele tocado.

\footnotetext{
${ }^{4}$ A teoria pós construtivista e alguns estudos cognitivos (Mark Johnson) e as novas noções de ambientalidade, espacialidade e territorialidade também propostas por Paul Virilio contribuem para o entendimento de novos desdobramentos epistemológicos neste contexto múltiplo de realidades. A teoria, assim como a prática audiovisual, enfrenta novas formas de atuação e de diálogo na ausência de fronteiras enunciativas e epistemológicas entre saberes antes apartados, - como de território e história, lugar e mapa, política e corpo, autoria e forma.
} 
Esse lugar do meio é o de toda potência criativa, plena de visualidades (soluções estéticas possíveis, criadas pelo corpo) e de visibilidades (estados disponíveis de criação de formas, criadas no corpo) -sendo o mesmo espaço aberto da ruína (que deixa de ter um significado homogêneo) e da fronteira (que passa a fazer sentido como lugar de encontro e não como separação, de um todo que não existe). Ruína e fronteira se fazem visíveis ao atuar nos entremeios das narrativas do corpo e das linguagens midiáticas. O discurso ao meio: a fala fraturada do lugar em sua própria porosidade.

Como, nesses termos representar o mundo do outro? Um estudo destes corpos nômades que constroem suas realidades no contexto revela-se imprescindível para reinstaurar um lugar de necessária reinvenção de si mesmo. Criar meios que melhor representem os acontecimentos desde um ponto de vista e de escuta pessoais (assim munidos de formas que representem a realidade que percebemos e vivemos) as ações no corpo e no mundo é tarefa tão científica quanto inventiva, e que requer um entendimento das narrativas como uma ação porosa, aderente, e que se dá no contexto de cada (não) lugar.

Os discursos que persistem se apresentam em novas formas e espaços de visibilidade e processamentos de comunicação, onde deslocar e (não) pertencer denunciam uma noção de lugar que deixa de ser física. Habitar um território aberto (zonas de transição, campos de refugiados) torna também o corpo um fenômeno imapeável. A construção de imagens passa a lidar com o espaço como paisagem e com a visibilidade como estratégia.

O afeto como possibilidade de perenidade, as intensidades individuais atualizadas nos deslocamentos, cada narrativa que parte da condição pré-sígnica para se configurar num novo espaço corpóreo de representação de si. Do mesmo modo, qual é a configuração epistemológica de novos estudos que abarquem o corpo, a estética, senão um conjunto maior que suas somas? E, certamente, de autorias menos cêntricas e mais nômades?

A territorialização (no território como corpo estendido, no corpo como território) ocorreria "quando um ambiente se qualifica e o entorno deixa de ser qualquer um". Em outras palavras, territorializar é a "ação de um corpo que cria novos sentidos em um lugar que passa a agir como significante e como meio". (Greiner, 2015: 106) Abordar o território como espaço de criação é, portanto, lidar com o caos, assim como lidar com vazios deste corpo que irá se compor a partir de trocas, ou desejos de significação, em suas realidades diluídas mapeamentos pessoais.

Os filósofos Gilles Deleuze e Félix Guattari afirmam que as sociedades modernas se definem pelos processos de desterritorialização. Para eles, territorializar é qualificar um ambiente, deslocando-o de um contexto e criando outro, numa reorganização sígnica. Estar situado, portanto, é estar deslocado. "A mobilidade 
incessante das situações subjetivantes e a arte como o deslocar no lugar do outro, gesto que abre o lugar ao outro, que se converte na promessa de meu próprio lugar e do lugar de todos nós" (Cesar, 2014: 114).

\section{A fronteira como lugar}

Na mitologia grega, Poros é a divindade ligada às situações de impasse e aporias. É também o pai de Eros. Poro, em português, remete à porosidade, aderência, superfície da pele, e nesta investigação como espaço fronteiriço entre culturas e signos: a pele como território, o corpo simultaneamente enquanto agente mantenedor da diferença e da singularidade. O contexto das aporias é o da criação como instrumento possível para as protagonistas desta pesquisa em seus processos inéditos de configuração de sentidos criativos e formas estéticas no contexto do deslocamento no lugar do aberto.

A fronteira como pele: no lugar poroso onde a comunicação de saberes é instrumento de sobrevivência -troca-se comida, roupa e olhares. Se hoje conflitam movimentos cada vez mais nômades e passagens cada vez mais vigiadas, este lugar do meio é o da troca entre tensões e incongruências. Superfície de embates de todo tipo -sociais, políticas, históricas e de relações de poder, a epiderme é permeável. Perceber o outro neste contexto de possibilidade elucida e aponta para evoluções teóricas e confluentes tanto quanto experimentais. Sugiro o entendimento de um ato performativo num corpo que sempre se refaz, que resiste/ existe em sua porosidade. Pois a pele é escritura viva, mapa do corpo sem centro nem direção, escrita por seus rastros de intensidades.

Que tipo de imagens criar no estado de aporia? Os discursos do corpo, mais ou menos perceptíveis, têm em comum com a imagem cinematográfica quatro qualidades: o tempo, o movimento, a imagem, o gesto. Considerando o cinema como performance do corpo, como defendo em minha tese (no Programa de Comunicação e Semiótica, PUC SP, 2011), isto é, como manifestação e apresentação de formas e conteúdos sempre móveis no trânsito com o ambiente (externo ou fílmico) e com o lugar (criado cenicamente ou socialmente) e em cuja obra (audiovisual) o tempo também se presentifica assim como no corpo, a natureza das imagens propostas para este experimento é performática e processual, em estado de evento, mostrando-se como a linguagem midiática que melhor possibilita criar formas estéticas e expressivas para os conteúdos do corpo destas artistas migrantes -que têm seus processos criativos também fluidos e processuais.

Para a brasileira Marisa Flórido Cesar (2014: 20), as unidades se desenham no descentramento; ela aponta para "conexões epidérmicas e rizomáticas e complexas relações de poder". Os vagalumes de Didi-Huberman (2011), seres frágeis que sobrevivem por singularidades e constantes exercícios de resiliência, à beira do 
desaparecimento, como cada corpo com suas histórias e tradições, traços de visibilidade em múltiplas direções. Da unidade do todo se perfazem circuitos sensórios e de criação de sentidos convergentes. Esta insistência no viver fortalece o lugar da semiose e o da produção de imagens: deslocar para preservar.

O lugar da porosidade no corpo é o de contato com o ambiente e com a cultura, o espaço das "microconstelações" onde indivíduos se aproximam e se afastam, redesenhando estas geografias diluídas. Didi-Huberman sugere que a imagem "nos oferece algo próximo a lampejos (lucciole)" (2011: 85). "É portanto não ver o espaço -intermitente, nômade, situado no improvável-das aberturas, dos possíveis, dos lampejos, dos apesar de tudo. (...) Haverá apenas sinais, singularidades, pedaços, brilhos passageiros - vagalumes" (42).

"Atravessamos as fronteiras e elas também nos atravessam; dispositivos de poder modelam novas formas de vida e incidem sobre o desejo e a linguagem" (Cesar, 2014: 18). Nesses contextos:

Criamos nossos próprios percursos transversais de significação. Que fronteira é essa que nos constitui? Todo território já contém vários níveis de desterritorialização (...). Nessas fronteiras e mundos móveis erguidos e diluídos o "onde", vórtice de onde as noções usuais de cidadania, nação e identidade também se deslocam em passagens que negam ancoragem (Cesar, 2014: 143; 148).

Para Franz Kafka,

as coisas do mundo nunca se apresentam desde as raízes, mas de um ponto qualquer situado em seu meio". Na fronteira, que "des-loca" a experiência convencional, o homem aparece nu, suspenso à história. É impossível tentar recompor a unidade perdida, os fragmentos disseminados (...). Livre das pretensões do eu legislador, as dinâmicas psíquicas repatriam em si o imaginário (apud Maldonato, 2014: 148;152).

Corpo e imagem se aproximam de suas qualidades primeiras, imprevisíveis, como é a memória, que revive acontecimentos, e a fantasia que alimenta um novo de infinitas contingências e potências no tempo do agora.

\section{Referências}

Agamben, G. (2012). Ideia de prosa. São Paulo: Editora 34.

(2007). Lo abierto. Buenos Aires: Adriana Hidalgo.

Cesar, M. F. (2014). Nós, o outro, o distante na arte contemporânea brasileira. Rio de Janeiro: Circuito.

Didi-Huberman, G. (2011). Sobrevivência dos vagalumes. Belo Horizonte: UFMG.

Greiner, C. (2015). Leituras do corpo no Japão e suas diásporas cognitivas. São Paulo: n-1 edições. 
Gumbrecht, H. U. (2010). Produção de presença. O que o sentido não consegue transmitir. Rio de Janeiro: Contraponto / PUC Rio.

Maldonato, M. (2014). A subversão do ser. Identidade, mundo, tempo, espaço: fenomenologia de uma mutação. São Paulo: SESC.

Silva, F. L. (2012). O outro (2012). São Paulo: Martins Fontes.

Silva, M. T. (2011). Imagem e ação: para um cinema do corpo. Tese de Doutorado defendida no Programa de Pós-Graduação em Comunicação e Semiótica, PUC-SP.

(2016). Mulheres continentais: performance de imagens na invenção de si. In: Menotti, G; Bastos, M.; Moran, P. (orgs.) (2016). Cinema apesar da imagem. São Paulo: Intermeios.

Sobreira, J. (2008). O fazer-dizer do corpo: dança e performatividade. Salvador: EDUFBA.

Uno, K. (2012). A gênese do corpo desconhecido. São Paulo: n-1 edições. 


\section{Anexos (frames de vídeos da autora)}

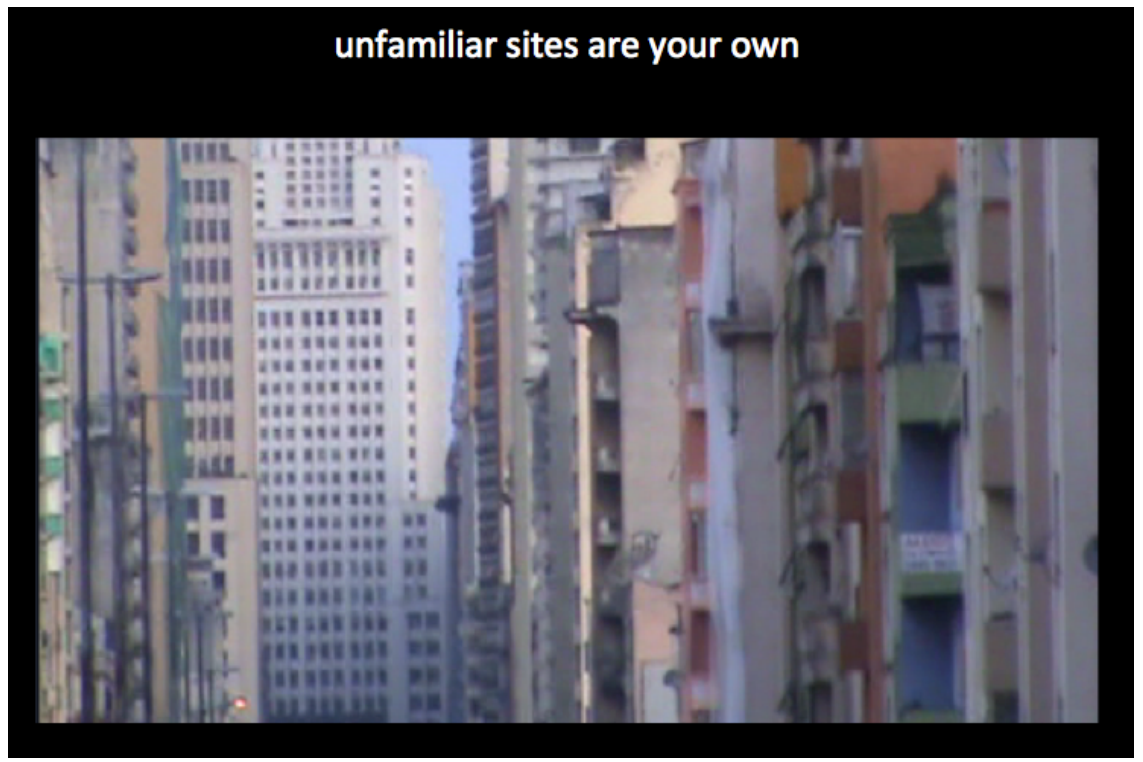

to fill an unknown memory with affections 


\section{landscape your own map}

\section{living things are your gestures too}




\section{jump and drop things to have}

\section{sliding presences have no place}


Panambí n. 5 Valparaíso dic. 2017 ISSN 0719-630X. 35-53. DOI: 10.22370/panambi.2017.5.1039.

no-bodies moves

\section{absences' shine}

